\title{
Converting Maturing Nuclear Sites to Integrated Power Production Islands
}

\author{
Charles W. Solbrig \\ Department of Pyroprocessing Technology, Idaho National Laboratory, ID 83415, USA \\ Correspondence should be addressed to Charles W. Solbrig, charles.solbrig@inl.gov
}

Received 6 May 2011; Accepted 18 August 2011

Academic Editor: Anis Bousbia Salah

Copyright () 2011 Charles W. Solbrig. This is an open access article distributed under the Creative Commons Attribution License, which permits unrestricted use, distribution, and reproduction in any medium, provided the original work is properly cited.

\begin{abstract}
Nuclear islands, which are integrated power production sites, could effectively sequester and safeguard the US stockpile of plutonium. A nuclear island, an evolution of the integral fast reactor, utilizes all the Transuranics ( $\mathrm{Pu}$ plus minor actinides) produced in power production, and it eliminates all spent fuel shipments to and from the site. This latter attribute requires that fuel reprocessing occur on each site and that fast reactors be built on-site to utilize the TRU. All commercial spent fuel shipments could be eliminated by converting all LWR nuclear power sites to nuclear islands. Existing LWR sites have the added advantage of already possessing a license to produce nuclear power. Each could contribute to an increase in the nuclear power production by adding one or more fast reactors. Both the TRU and the depleted uranium obtained in reprocessing would be used on-site for fast fuel manufacture. Only fission products would be shipped to a repository for storage. The nuclear island concept could be used to alleviate the strain of LWR plant sites currently approaching or exceeding their spent fuel pool storage capacity. Fast reactor breeding ratio could be designed to convert existing sites to all fast reactors, or keep the majority thermal.
\end{abstract}

\section{Introduction}

Nuclear islands, which are integrated power production sites, could effectively sequester and safeguard the US stockpile of plutonium. A nuclear island, an evolution of the integral fast reactor [1], utilizes all the tranuranics (TRU (Pu plus minor actinides)) produced in power production, and eliminates all spent fuel shipments to and from the site. This latter attribute requires that fuel reprocessing occur on each site and that fast reactors be built on site to utilize the TRU. The most straightforward way to eliminate all commercial spent fuel shipments would be to convert existing LWR nuclear power sites to nuclear islands since all the commercial spent fuel is currently stored on these sites.

These existing sites have the added advantage of already having a license to produce nuclear power which should allow easier licensing of added on-site nuclear plants. Assuming that nuclear power would increase with at least the same rate as the increase in electrical power in the US, these sites could contribute to this increase in the nuclear power production by adding two or more fast reactors to each site. Doubling the electrical power over the next 40 years could easily occur [2]. Just a $2 \%$ increase in electrical power requirements per year would result in over double the power in 35 years. The study shows how an existing nuclear site with sufficient room and two thermal reactors nearing the end of an initial 40-year license but with a 20 -year extension could be converted to a four-reactor fast reactor site within a 40 year time frame with no spent fuel shipments off-site. The waste form will only include fission products resulting in a 300 year storage project rather than a 10,000 year one. The fission product waste forms developed [3] are the only products to be shipped to a waste repository. Several other options are investigated with lower and higher power increases, and with complete conversions to fast reactors or with retaining several thermal reactors but all have the characteristic of no spent fuel shipments off-site.

The number of power plants that can be built and powered by reprocessed fuel obtained from the spent fuel resulting from 40 years of operation at a site depends upon the breeding ratios of the fast reactors, the throughput of the reprocessing plant added to the site, and how long the thermal reactors continue to operate with license extensions. Both the TRU and the depleted uranium obtained from 
reprocessing would be used on site for fast fuel manufacture. Only fission products would be shipped to Yucca Mountain for storage and only depleted uranium would have to be shipped to the site to make up for the uranium that is converted to TRU. Both the thermal spent fuel and the fast reactor spent fuel will be processed.

To minimize the nuclear proliferation threat, the model here assumes that reprocessing of oxide spent fuel from the thermal reactors will be reduced to metal and then the Argonne developed electrochemical process [4] will be used to separate the spent fuel into fission products, transuranics, and depleted uranium. Since each nuclear island would have reprocessing capability, nuclear proliferation could become an important issue and would make use of a chemical separation process like Purex less likely to be acceptable because plutonium is separated as an individual product. Plutonium is susceptible to diversion because of its low radioactivity. The Argonne electrochemical process is only able to separate out the transuranics (which contains $90 \%$ $\mathrm{Pu}$ ) as a group which has lethal amounts of radioactivity and more difficult to divert. Processing of these metallic transuranics into fast reactor fuel must be done in a hot cell environment with its attendant five-foot-thick walls for radiation protection and the difficulty and high probability of personal demise in diverting this material. Central station reprocessing using the same nonproliferation technology has also been studied [5].

The nuclear island concept could be used to alleviate the strain of those LWR plant sites currently approaching their spent fuel storage limit or which have exceeded it and are now installing dry storage racks. Five scenarios are presented, each starts with a light water reactor (LWR) plant site with two 1000 MWe LWRs nearing their 40-year license with spent fuel pools reaching saturation. A reprocessing plant of $100 \mathrm{MTHM} / \mathrm{yr}$ would be added to the site. The site would have sufficient spent fuel to supply plutonium for the initial loading of two fast reactors, the first of which would be built in four years. The fast reactors would be designed with a specified breeding ratio. Three different breeding ratios are studied in these scenarios, $0.5,1.0$, and 1.3. The objective of using a breeding ratio of 0.5 would be to convert all the spent fuel from the thermal spectrum plants but not increase the power output. Designing a fast reactor with a higher breeding ratio would increase the number of reactors and thus the power at the site. Reactors with breeding ratios of 0.5 would not use blanket assemblies and would be designed to lose neutrons. Enough DU exists in the fuel rods themselves for a 0.5 breeding ratio. The higher breeding ratio reactors would include blanket assemblies and more efficient geometries to capture more neutrons.

The purpose of this paper is to investigate different scenarios for the nuclear island development in terms of increasing power with breeding ratio, size of reprocessing plant on each site, and length of operation of the thermal plants. The following section discusses the benefits of the nuclear island concept. This is followed by a section which briefly describes the model used to estimate these scenarios. Then a results section follows which investigates these scenarios. Within 40 years from now, all nuclear power plant sites in the US could be on their way to becoming nuclear islands and to doubling or tripling their power output.

\section{Cost/Benefit and Nuclear Risk/Public Perception Considerations}

This paper recommends that existing two-reactor LWR nuclear sites be converted to nuclear islands which starts by adding a $100 \mathrm{MTHM} / \mathrm{yr}$ reprocessing plant to the site. This is instead of building a single centralized reprocessing facility to reprocess fuel. A centralized plant would require the shipment of radioactive spent nuclear fuel from all operating reactors in the country to the reprocessing facility and the transport of the reprocessed fuel back to the reactor sites. The nuclear island concept eliminates this transport and the possible accidents and diversion potential associated with it. The $100 \mathrm{MTHM} / \mathrm{yr}$ reprocessing plant has been under design for many years at Argonne and hence could be built faster than a large $3500 \mathrm{MT} / \mathrm{yr}$ plant. Prototype equipment in $100 \mathrm{MTHM} / \mathrm{yr}$ size range has been in operation for several years [6]. The cost requirements for reprocessing plants in order to be competitive with existing thermal fuel production have been presented in another article [7]. Current reprocessing plants being built or planned have much higher costs than those presented in the article but the cost objectives should be feasible. The real benefit of the nuclear island concept scheme for conversion to fast reactors is that it is evolutionary, can be implemented now starting on existing nuclear plant sites, and can methodically add increased power output to existing reactor sites to provide fuel reprocessing and breeder reactors periodically during the 40-year conversion period. The alternative of building a large central reprocessing plant and breeder reactors is revolutionary, would take years to site, take decades to build, and decades to build and site fast reactor plants at new sites along with decontamination and decommissioning of existing reactors before useful power output is achieved.

Combining a power production plant with a fuel reprocessing plant could increase the risk of environment contamination in case of a major accident because more is being done but the increase is very small. The increase would be much smaller than adding another reactor plant to the site. The facilities would act independently in an accident because the facilities are not connected except for fuel transfers. The common mode failure would be loss of power. Reprocessing is done behind 5-foot-thick walls of concrete in an inert argon atmosphere to prevent reaction of the metal fuel with oxygen during production. The design base accident is an earthquake that ruptures the cell boundary and lets air in which reacts with exposed metal fuel. The amount of exposed metal fuel is small and the fuel is kept in earthquake-proof and leak- proof containers until needed. In the prototype fuel cycle facility being operated at the Idaho National Laboratory, the only boundary rupture possible is from small penetrations that go through the five foot thick concrete wall. The design of the commercial facility will make the boundary earthquake proof so that this accident will not be possible. Also, there is no possibility of criticality caused by any natural 
disaster such as earthquake because of the separation of all the fuel. The cooling requirements are small, and in the event of a loss of cooling incident where cooling cannot be reinitiated, the cell temperature would increase so that the heat generated would be lost through the walls. Other minor incidents are possible and have been analyzed and shown to be benign.

The public perception of nuclear power risks has increased due to the Fukushima plants that were damage by the Japan tsunami. But this is only a temporary setback since nuclear power must be eventually embraced as the major power source. It is the only significant power source with low risk and minimal environmental damage. Incidents like Fukashima can only delay what must eventually occur, which is the conversion to nuclear power as the major power source. The reality is that no one was killed or received significant doses of radiation as a result of the damage to the Fukushima nuclear facilities. But 25,000 people were killed by the tsunami and that is where the focus should be, not the blow-by-blow description of what is going on to shut down the nuclear facilities. It is a financial disaster, not a disaster to humans.

Nuclear energy is an 80 to 90 percent solution to the energy problem. The other renewables, which should be used as much as practical, are each, at most, a 5 to 8 percent solution. Wind and Solar are the most promising. Solar power which has the most potential, is being implemented incorrectly with central station paneling of large land areas, or large arrays of mirrors for thermal plants. Instead, the roofs of all existing homes and building should be used to obtain the needed areas with little eye pollution or excessive waste of land. Wind generators, dotting hills, mountain ridges, and oceans often end up becoming the object of protests when they ruin the view and produce power which is not available locally but exported to states that require their utilities to supply $15 \%$ green energy but do not want wind farms themselves. Both wind and solar energy are marketed in terms of maximum capacity when in fact they operate only 30 percent of the time. Utilities don't want to build solar or wind plants because they still must provide full backup power facilities for the times that solar or wind are not providing power. All the reasonable water power sites have been built in the US and any further capacity is extremely expensive and subject to large protests because of the use of large land areas, some of which are populated. The dam failure risk to large population centers downstream of dams is accepted or usually not recognized. Dam failures occur every year.

Besides the continuing thermal pollution from fossil fuel plants, they consistently produce real disasters. Natural gas produces pipeline explosions, house explosions, asphiations, explosions caused by penetrating buried pipelines during construction, and so forth. These accidents are barely covered by the press. Coal mining, oil disasters, and all of these deaths and destruction from these disasters are covered by the press as expected (and acceptable). But nuclear incidents are treated in an irrational manner and serve to delay the eventual construction of needed electrical production. Nuclear plants plus the plug-in hybrid car are the best hope the US has for energy independence and reduction of $\mathrm{CO}_{2}$ emissions.

\section{Description of Model}

Each site is assumed to start out with two 1000 MWe thermal spectrum plants. All the results can be applied to any other site by scaling the results by the ratio of actual to the 2000 MWe assumed here.

The heavy metal in the annual spent fuel product from a 1000 MWe thermal spectrum plant is $20.7 \mathrm{MT} / \mathrm{Yr}$,

$$
\begin{aligned}
D_{\mathrm{TR}} & =\frac{3000 \mathrm{MW} * 365 \text { days } *(\text { capacity factor }=0.85)}{45,000 \mathrm{MWd} / \mathrm{MTHM}} \\
& =20.7 \mathrm{MTHM} / \mathrm{GW} .
\end{aligned}
$$

The reactors are assumed to operate for 40 years producing the 20.7 MT of heavy metal (HM) each year. A processing plant of $100 \mathrm{MT} / \mathrm{Yr}$ is assumed to start operation in year 41 of reactor years and year 1 of reprocessing. It is assumed that construction of this plant began four years before. Results in Section 3 are presented in reprocessing years.

Transuranics approximately make up $1 \%$ of the spent reactor fuel. Transuranics are made up of $90 \%$ plutonium and $10 \%$ of the minor actinides americium, curium, and neptonium. Therefore the TRU harvested annually from $100 \mathrm{MT} / \mathrm{Yr}$ reprocessing plant is $0.01 * 100$. When enough TRU has been harvested in reprocessing to fabricate fuel for a fast reactor core, a fast reactor is loaded and started up. It is assumed that plant construction was started five years before that time and is now complete. The amount of TRU fuel needed to fuel a fast reactor core is $4 \mathrm{MT}$. Two reloads are needed in addition to the initial core load before new TRU fuel can be assigned to the second fast reactor. A core reload is $1 / 3 \mathrm{rd}$ of an initial core. One-third of the core is replaced every 1.5 years so that a complete core changeout occurs every 4.5 years. The $1 / 3 \mathrm{rd}$ of the core taken out and replaced by the reload is referred to as an xload. The first xload must decay for at least one year after being taken out of the reactor before it can be processed. To simulate the above in a model with year-to-year increments of time, it is assumed that the $4 \mathrm{MT} / 4.5 \mathrm{Yr}=0.889 \mathrm{MT} / \mathrm{Yr}$ spent fuel is removed from a fast reactor. Then a two-year delay is assumed before it can be processed.

The net amount of TRU which must be supplied annually to fuel a fast reactor is $0.889 *(1-\mathrm{BR})$. In this model, $0.889 \mathrm{MT}$ of TRU is taken from the TRU fuel reservoir as input to the reactor and the $0.889 * \mathrm{BR} \mathrm{MT}$ is added to the TRU reservoir after the fast fuel is processed (two years after). The TRU which is fissioned in a year can also be estimated by

$$
\begin{aligned}
M_{\mathrm{TRU}} & =\frac{3000 \mathrm{MW}_{\mathrm{t}} * 365 \text { days } *(\text { capacity factor }=0.85)}{\mathrm{MW}_{\mathrm{t}} \mathrm{d} / 0.95 \mathrm{gm}} \\
& =0.889 \mathrm{MTTRU} / \mathrm{GW} .
\end{aligned}
$$

Spent fuel from both thermal and fast reactors (referred to here as thermal and fast spent fuel) are processed in the 
same facility so that in a $100 \mathrm{MT} / \mathrm{Yr}$ facility, if $9.3 \mathrm{MT} / \mathrm{Yr}$ of fast spent fuel is processed, then only $90.7 \mathrm{MT} / \mathrm{Yr}$ of thermal spent fuel can be processed. For each operating fast reactor, 9.3 tonnes of HM are produced as spent fuel annually. This contained the 0.889 MT of TRU when it was loaded into the core,

$$
\begin{aligned}
D_{\mathrm{FR}} & =\frac{3000 \mathrm{MW} * 365 \text { days } *(\text { capacity factor }=0.85)}{100,000 \mathrm{MW}_{\mathrm{t}} \mathrm{d} / \mathrm{MTHM}} \\
& =9.31 \mathrm{MTHM} / \mathrm{GW} .
\end{aligned}
$$

The fuel downloaded from a fast reactor each year that must be processed is $9.3 \mathrm{MT} / \mathrm{Yr}$. This quantity is assumed independent of the amount of TRU in it (i.e., the breeding ratio). This is actually true only for $\mathrm{BR}=0.5$ because it will not have blanket assemblies. For larger breeding ratios greater than 0.5 , they will have blanket assemblies which must be processed also to get the TRU that is produced in them [4]. For BR $=1$, this is approximately an increase of $25 \%$. This effect has not been included in the model but should not change the conclusions drawn.

Reprocessing of fast fuel takes precedence over processing thermal fuel because less fast fuel needs to be processed to produce a unit of TRU fuel than thermal fuel. So 9.3 tonnes of spent fuel from the fast plant must be processed to produce $0.889 *$ BR MT of TRU. For BR $=0.5,20.9$ tonnes of this spent fuel must be processed to produce one tonne of TRU fuel. For $\mathrm{BR}=1.0,10.46$ tonnes of this spent fuel must be processed to produce 1 tonne of TRU fuel. From a thermal plant 100 tonnes must be processed to produce one tonne. In addition, the front end oxide reduction process is not performed to process the metallic spent fuel from the fast reactors. Thus, it is less expensive to reprocess the fast fuel.

The change in the amount of nonprocessed spent thermal fuel NPF (i.e, the thermal fuel left to process) is equal to the amount added from the number of thermal reactors (GWT) that year minus the amount of thermal fuel processed last year, THMP,

$$
\mathrm{NPF}_{i+1}=\mathrm{NPF}_{i}+\mathrm{GWT}_{i+1} * 20.7-\mathrm{THMP}_{i}
$$

The reprocessing plant throughput (HMP) is limited by the size of the plant (RPS) as well as the amount of spent fuel available to process, that is, the fast reactor fuel to process (FRFP) plus the nonprocessed thermal fuel. In a given year:

$$
\mathrm{HMP}=\mathrm{MIN}(\mathrm{RPS}, \mathrm{FRFP}+\mathrm{NPF}) .
$$

Most of the thermal spent fuel will be aged at least several years before it is processed. In the cases where the thermal reactors are shut down several years before all the thermal fuel has been processed, all the fuel will be aged. In some scenarios where the thermal plants continue to run, this is not true in the later years. In the later years in scenarios where thermal plants continue to run, thermal spent fuel is processed in the year it is produced. Although there should be a delay in reprocessing this fuel, his effect has been neglected in this model but including the effect would not affect the conclusions.
The annual change in TRU fuel in the reservoir is equal to 0.01 times the thermal fuel reprocessed each year minus the amount used to fuel a fast reactor core minus the amount used in core reloads plus the amount harvested from reprocessing fast reactor fuel. In mathematical notation, this change is represented in the following equation. Each term mentioned above corresponds to each of the terms below

$$
\begin{aligned}
\mathrm{TRU}_{i+1}= & \mathrm{TRU}_{i}+\mathrm{THMP}_{i+1} * 0.01-\left(\mathrm{GWF}_{i+1}-\mathrm{GWF}_{i}\right) * 4 \\
& -\mathrm{GWF}_{i+1} * 0.889+\mathrm{GWF}_{i-1} * 0.889 * \mathrm{BR} .
\end{aligned}
$$

The TRU reservoir is used to estimate when to start a new fast reactor plant. If starting causes the TRU to go negative, then the plant is delayed a year or more until the TRU does not enter into negative territory.

\section{Results}

Fast reactors can be designed to produce the breeding ratio most conducive to either reducing plutonium or to producing power, to convert existing sites to all fast reactors or to keep the majority thermal. Three scenarios are described using $\mathrm{BR}=0.5, \mathrm{BR}=1.0$, and $\mathrm{BR}=1.3$ to convert 2 thermal plant sites to nuclear islands resulting, respectively, in 2, 4, or 6 fast reactors. In addition, two scenarios are presented where sites are converted to two thermal reactors, two fast reactor nuclear islands or to four thermal reactors, and two fast reactor nuclear islands. The scenario chosen in the US will depend upon the future power increase needed from nuclear reactors and what percentage of fast reactors will be allowed. It must be a minimum of 33\%. Without the fast reactors, there can be no nuclear island.

4.1. Site Conversion from Two Thermal to Two Fast Spectrum Plants $(B R=0.5)$. A breeding ratio of 0.5 used in the fast reactors added to a reactor site will allow it to be converted from a two thermal reactor site to two fast reactor sites over a 40 -year time frame. As in all these examples, the site initially contains two $1000 \mathrm{MWe}$ unit thermal reactors. Construction of a $100 \mathrm{MT} / \mathrm{Yr}$ reprocessing plant construction begins 36 years after initial operation of the thermal plants. The reprocessing plant is completed in year 40 and begins reprocessing spent fuel. Simultaneously with the start of reprocessing, construction on a 1000 MWe fast reactor plant is begun. The processing consists of reducing spent oxide fuel to metal and electrorefining the metal to produce TRU, DU, and fission products. The TRU and DU are processed to produce metallic fast reactor fuel of the type developed in EBR-II and the fission product waste form is sent to Yucca Mountain for 300-year storage [5]. The fission product waste form has one-fifth the heat and volume of the original spent fuel and only uses one-fifth the space.

At the end of four years of operation, enough fuel has been processed to fuel a fast reactor. The fast reactor is assumed to be built, to be ready to accept this core, and to begin operation. Another three years are required to produce the two reloads (each $1 / 3$ core) needed for operation. The 


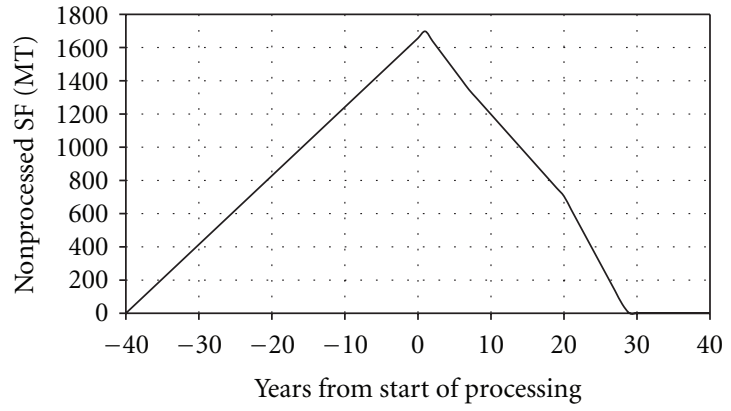

(a) Thermal reactor spent fuel inventory

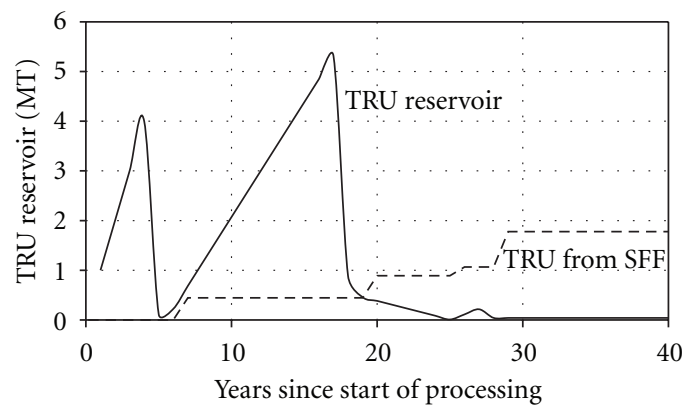

(c) TRU reservoir with modified increase in breeding ratio

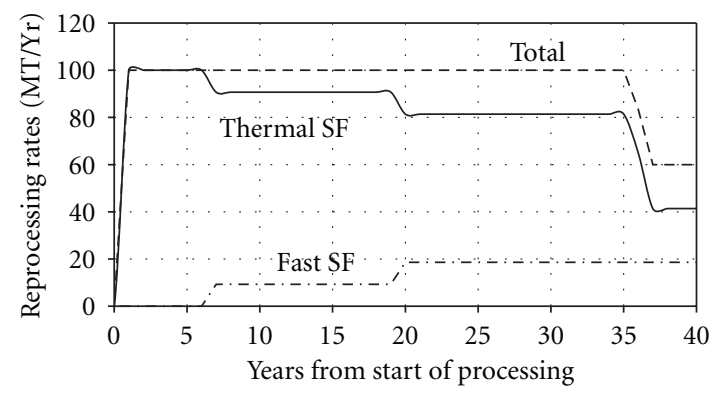

(e) Reprocessing rates needed for continued thermal plant operation

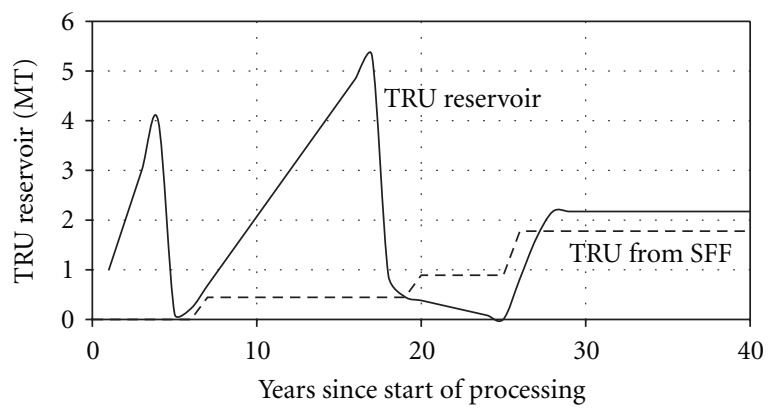

(b) Time history of TRU reservoir

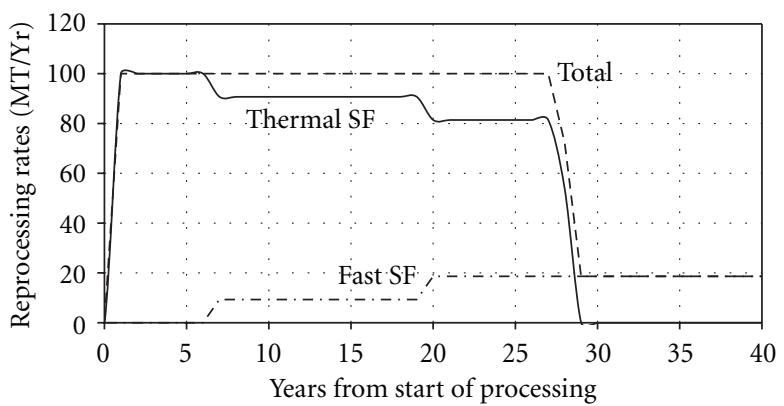

(d) Time history of the reprocessing

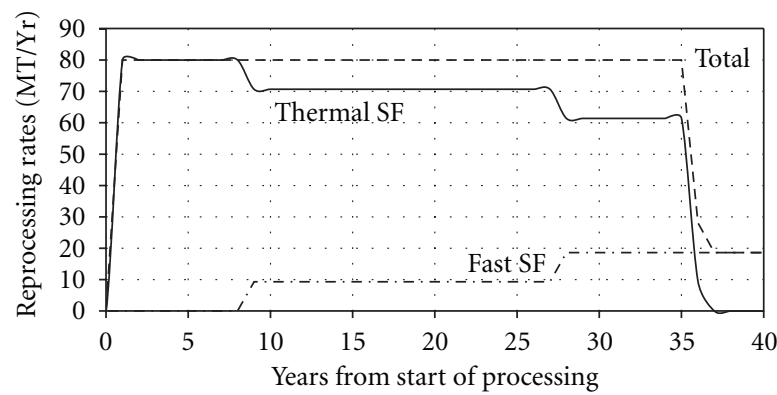

(f) Effect of reducing reprocessing plant size

FIGURE 1: Site conversion from two thermal to two fast spectrum plants $(B R=0.5)$.

first reload is needed after 1.5 years of operation, at which time, it is inserted in the core and the first xload is removed from the core to allow it to cool for one to two years before reprocessing can occur. Since an electrochemical process is being used, only one or two years of cooling are required before reprocessing can occur. After another 1.5 years, the second reload is inserted in the core and the second xload is removed. The first xload is now added to the reprocessing line since it has cooled long enough. It produces more TRU/MT of spent fuel processed than the thermal fuel and the amount depends on the breeding ratio designed into the fast reactor. Since the same reprocessing facility is used for both fast and thermal spent fuel, the spent fast reactor fuel processed reduces the amount of thermal fuel which is processed. The fast fuel has an advantage in processing in that it does not have to be reduced to metallic fuel since it is already metallic. Some of the thermal fuel which is processed at this time will be used to fuel the second fast reactor. The rate of TRU production which is allotted to the second reactor is reduced by the amount of TRU needed for reloads in the first reactor, which is high in this case because the breeding ratio is 0.5 .

The time history of non-processed spent fuel is shown in Figure 1(a) for this case. The spent fuel is seen to build up for the first 40 years of plant operation and to begin to decrease with the operation of the reprocessing plant. The rate of decrease is the largest during the fabrication of the first core load and two reloads which take seven years after the reprocessing plant commences operation. After that, the decrease in the nonprocessed fuel per year lessens because the fuel from the fast reactor must be processed and cuts down on the thermal fuel reprocessing. Eighteen years after processing begins, manufacture of the fuel for the second fast reactor is completed so the slope changes again. Two years after that, the two thermal plants are assumed to run out their license extension and are shut down. With no additional thermal spent fuel being generated, the stockpile of this spent fuel reduces to zero within another seven years. At that 
time, the supply of TRU fuel to the fast reactors becomes insufficient and the breeding ratio must be increased to one for continued operation of the reactors. For any scenario, such as this one, which ends up with only fast reactors, the breeding ratio must be adjusted to one.

The time history of the TRU fuel reservoir is shown in Figure 1(b). The first two precipitous drops are due to the new fast reactors coming on line when the core inventory of four metric tonnes of TRU is loaded. A delay of two years in the loading of the second reactor was taken in order to prevent a negative TRU inventory to occur due to additional fuel needed for reloads. The TRU inventory would have become negative in the year 26 . To prevent having to bring in TRU from an outside source, the breeding ratio of the fast reactors was changed to one at year 26. This change was adequate and caused the TRU reservoir to increase to about 2.2 metric tonnes and to stay at that value. All the archived spent fuel had been processed by year 29 . Thereafter, the TRU reservoir becomes constant because there are only two fast reactors which use as much TRU as they produce. The excess in the TRU reservoir can easily be reduced. For example, increasing the breeding ratio to 0.6 in year 26 for three years until all the archived spent fuel is processed and then to 1.0 yields the time history for TRU in Figure 1(c) which is almost zero after year 28. The TRU from spent fast fuel (SFF) is also shown in Figures 1(b) and 1(c).

Two problems are noted with this scenario. The first is that the total reprocessing rate shown in Figure 1(d) drops to the reprocessing rate for the fast reactor fuel in year 28 which means that the reprocessing plant is only used at $19 \%$ of capacity soon after the thermal plants are shut down when the thermal fuel has all been processed. The power output from the site is also a problem if an increasing power is desired since the power goes from $2000 \mathrm{MWe}$ to $3000 \mathrm{MWe}$ in year five, to 4000 MWe in year 18, and back to 2000 MWe in year 21 when the thermal plants are shut down.

Several possibilities exist for resolving these problems. The first would be to extend the license of the thermal plants by another 20 years and change the breeding ratio to 0.6 at year 26. This increased breeding ratio and the extra thermal spent fuel supplies enough TRU until the reservoir of spent fuel drops to just the amount added each year and then the breeding ratio must again be increased, say to 0.75 for the last four years. The reprocessing rate for this case is shown in Figure 1(e) where it is seen that the total reprocessing rate remains at $100 \%$ until the year 35 , which is not a benefit since it will cost more to run the plant at $100 \%$ for more years. A benefit is that the power remains constant until the year 40 since the thermal plants continue to operate. However, this scenario also has its drawbacks since the thermal plants will probably have to be replaced at year 40 , but there are only two fast reactors on the site with insufficient TRU to fuel more so that it may be necessary to replace the thermal plants with new thermal plants with the consequent requirement to supply fresh thermal reactor fuel. There is a tradeoff on cost with fast reactor plants being more expensive than thermal plants but supplying reload fast reactor fuel from reprocessing fast reactor spent fuel would be less expensive than from spent thermal reactor fuel.
4.2. Effect of Reprocessing Plant Size $(B R=0.5)$. Capital costs would be less if the reprocessing plant on each nuclear island were smaller, but this section shows that reprocessing plants on the order of $100 \mathrm{MT} / \mathrm{Yr}$ are close to ideal for nuclear islands. Much larger plants are appropriate if the decision is made to use central reprocessing [8] but would not work here. Much smaller would not work either. This section investigates a slightly smaller plant size and shows that it is just barely adequate. Figure $1(f)$ illustrates the effect on reprocessing when the plant size is reduced to $80 \mathrm{MT} / \mathrm{Yr}$.

It is seen that processing produces sufficient TRU fuel for the first fast reactor to begin operation in year 7 and the second to begin operation in year 26 . The breeding ratio is increased to 0.7 at the same time as the second plant starts up to supply sufficient TRU fuel. The spent fuel is completely reprocessed by year 36 and the breeding ratio must be increased to 1.0 at that time. The processing plant is used at full capacity out to year 35 . If the plant has reached its end-of-life at this time, it could be replaced by a smaller plant which only reprocesses the fast reactor spent fuel. A problem with this scenario is that when the thermal reactors are shut down in year 21 , there is only 1000 MWe being generated at the site until year 26 when the second fast reactor is started. If the thermal plants are extended to run to year 26 to provide more power, the thermal spent fuel will still all be processed by year 39 . Thus the smaller reprocessing plant size is practical but tends to delay when the conversion occurs to the fast reactors, so, is dependent upon being able to get a further plant life extension for the thermal plants.

Both this and the previous scenario with breeding ratios of 0.5 do not increase total site power but do convert the site from two thermal reactors to two fast reactors over 36 years. The breeding ratios of the fast reactors must eventually be increased to one toward the end of the first forty years of operation.

\subsection{Site Conversion from Two Thermal to Four Fast Spectrum} Plants $(B R=1.0)$. This case increases power from two thermal plants to four fast reactor plants and begins with the same assumptions as the previous section; however, the fast reactors utilize a breeding ratio of 1 in their design. Due to the quicker build up of TRU fuel, the fast reactors are brought online more quickly. The nonprocessed spent fuel inventory is shown in Figure 2(a). It takes slightly longer to process all the spent fuel in this case than the breeding ratio 0.5 case because more fast fuel must be processed to operate the fast reactors.

The TRU fuel inventory is shown in Figure 2(b). The large decreases again indicate when new fast reactor plants are brought online. Breeding ratio doesnot affect the initial plant, so, as before, it starts in year 5 . The second plant comes on much earlier at year 12. In year 21, the two thermal reactors will have produced enough spent fuel to supply plutonium for a third fast reactor. Even though the thermal plants are shut down at this time, there is still enough spent thermal fuel to process to produce enough TRU metallic fuel for a fourth fast reactor in year 26. There may be some logistic difficulty in replacing one of the thermal reactors in year 21 with a fast reactor which could cause some delay 


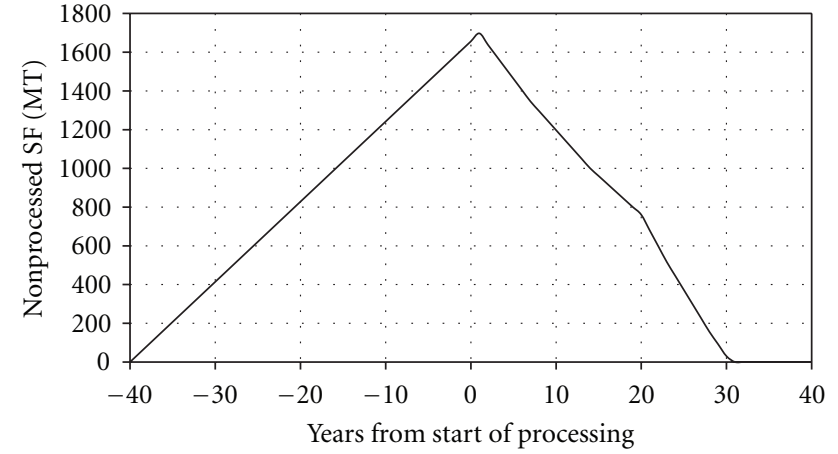

(a) Thermal reactor spent fuel inventory

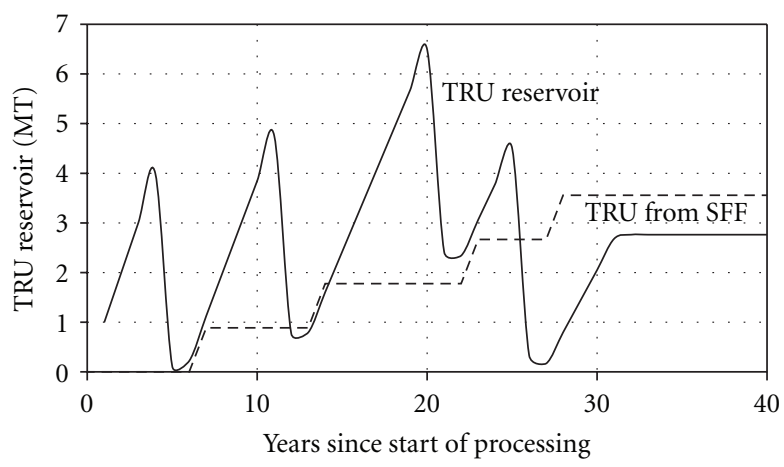

(c) TRU fuel inventory, thermal plants 60-65-year service

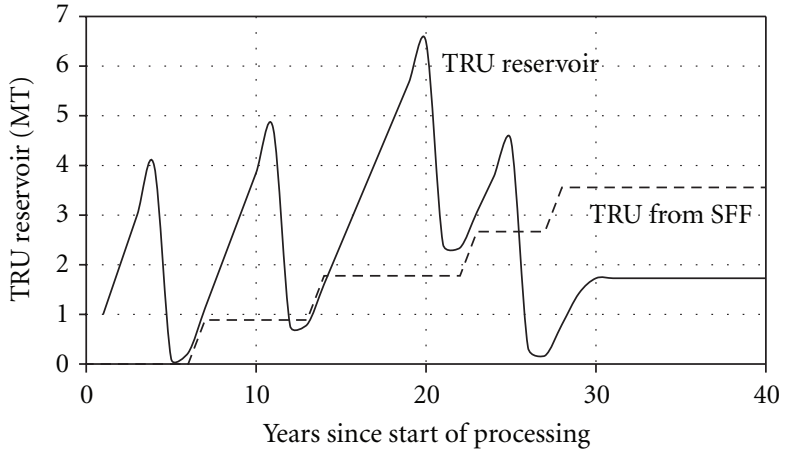

(b) TRU fuel inventory, thermal plants 60-year service

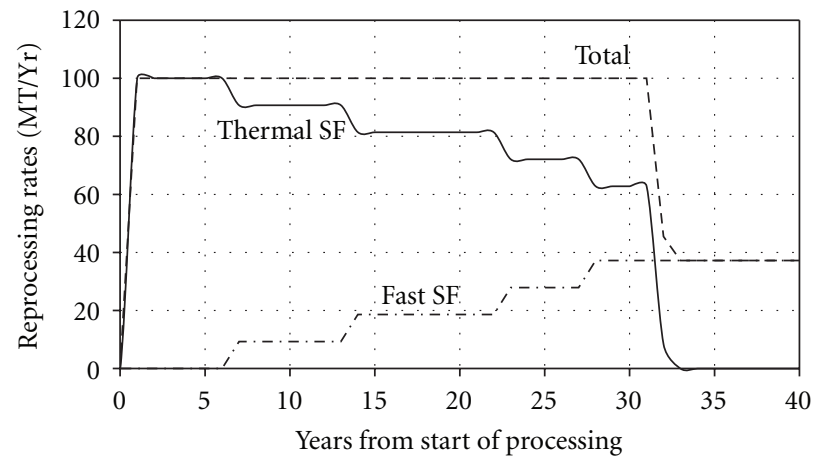

(d) Processing rates, thermal plants 60-65-years service

FIgURE 2: Site conversion from two thermal to four fast spectrum plants $(\mathrm{BR}=1.0)$.

in starting this reactor. This could cause additional TRU reservoir buildup in the steady state (i.e., after the fourth fast reactor is started up in year 26). If that buildup is undesirable or if the steady state value shown in Figure 2(b) $(1.8 \mathrm{MT})$ is too high or too low, the breeding ratio can be adjusted temporarily to bring the reserve into desired compliance. This scenario has a steady output of $4000 \mathrm{MWe}$ after the second fast reactor plant is started except for a five year period from year 21 to 26 when both thermal plants have been shut down and only three fast reactor plants are operating. Only one of the 60-year-old thermal spectrum plants should be retired from service at age 60 and the other operated until the fourth fast reactor comes into service. The TRU inventory is shown in Figure 2(c). The steady state inventory is higher since more thermal spent fuel was processed. Again, this could be lessened by using a lower temporary breeding ratio.

The reprocessing rates for this constant $4 \mathrm{GWe}$ power profile is shown in Figure 2(d). The reprocessing plant is utilized out to year 32 at $100 \%$ capacity and afterward at $40 \%$. The processing plant may only have a plant life of 32 years and would be replaced by a smaller $40 \mathrm{MT} / \mathrm{Yr}$ plant to process only the metallic fast reactor fast fuel.

\subsection{Site Conversion from Two Thermal to Six Fast Spectrum} Plants $(B R=1.3)$. This breeding ratio has the capability of converting two thermal reactor sites to more than six fast reactor sites and would apply to sites with enough room for these additional reactors. The nonprocessed fuel is shown in Figure 3(a). Processing all the spent thermal fuel takes longer than previous cases because of the added fast reactor spent fuel processed to operate the fast reactors.

The TRU fuel inventory is shown in Figure 3(b). The start of each fast reactor is indicated as before with drops in the TRU inventory of four MT. These reactors are started in years $5,10,16,19,23$, and 26 , respectively. The increase in power at the site occurs steadily. The first thermal reactor is assumed shut down in year 23 as the fifth fast reactor comes on line. Similarly, the second thermal reactor is shut down when the sixth fast reactor plant comes online in year 26. Thus the power output is kept constant at six GWe once the fourth fast reactor is brought on line.

In order to decrease the steady state TRU inventory, the breeding ratio may be reduced after the sixth fast reactor has been started. Figure 3(c) shows the effect of this reduction. The breeding ratio is reduced to 1 in year 27, then to 0.91 in year 28 where it is held constant until all the thermal fuel has been processed by year 38 . Then the breeding ratio is increased to 1.0 again in year 39 and kept constant.

The reprocessing rate, shown in Figure 3(d), runs at $100 \%$ out to year 37 and then reduces to $58 \%$ when all the thermal spent fuel is completed. So the reprocessing plant is used much more effectively in this scenario.

4.5. Site Conversion to Two Thermal and Two Fast Spectrum Plants $(B R=0.5)$. Due to the additional expense of fast 


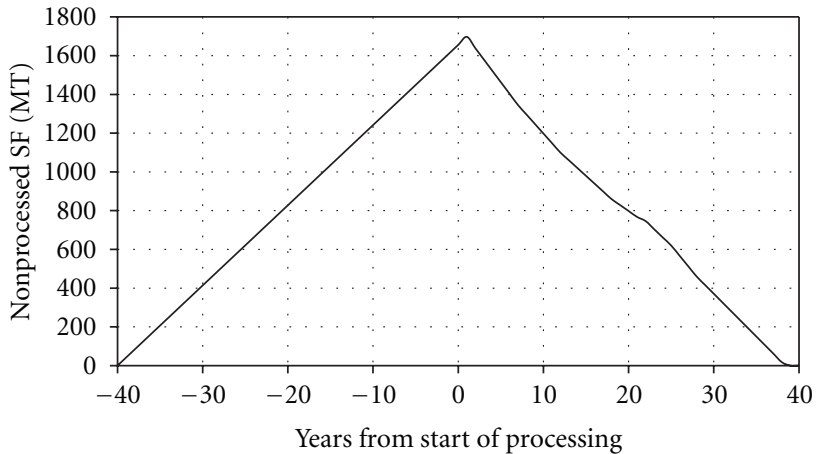

(a) Nonprocessed fuel inventory $(\mathrm{BR}=1.3)$

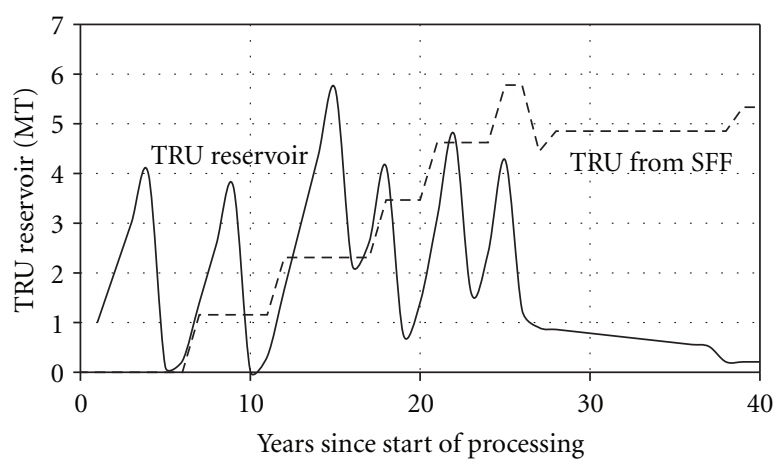

(c) TRU fuel reservoir ( $\mathrm{BR}=1.3$ then reduced to 0.91$)$

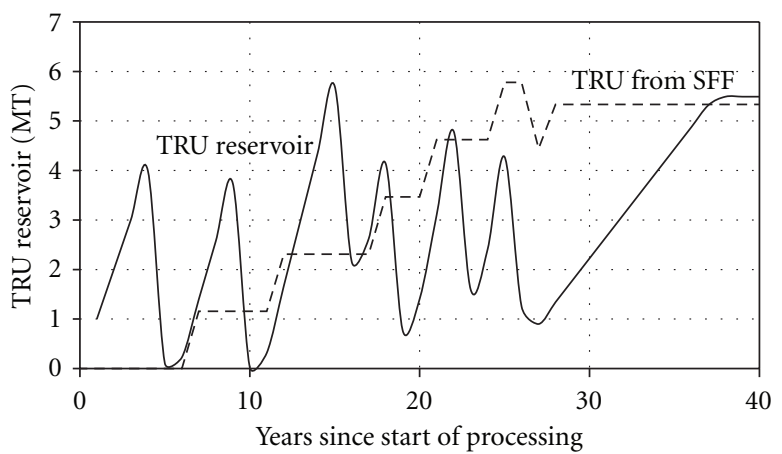

(b) TRU fuel inventory $(\mathrm{BR}=1.3)$

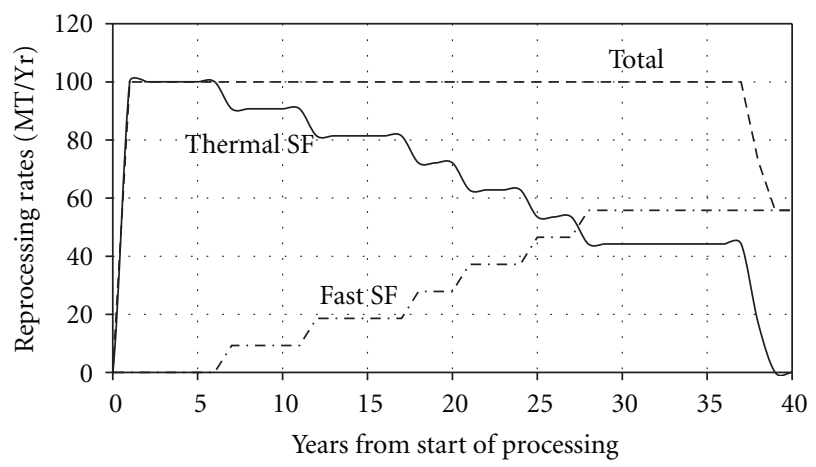

(d) Reprocessing rates $(\mathrm{BR}=1.3$ then reduced to 0.91$)$

FIgUre 3: Conversion from two thermal to six fast spectrum plants $(B R=1.3)$.

reactor plants over thermal plants, it may be more desirable to continue to use thermal plants even with no off-site shipments of spent nuclear fuel. The first two thermal plants are shut down after 60 years of operation but are replaced by two new thermal plants or the license extensions. Two fast reactors are added to the site in a similar manner as in the breeding ratio $=0.5$ scenario. The resultant TRU inventory is shown in Figure 4(a). The fast reactor plants are started in years 5 and 18. After the second fast reactor plant comes on line, the TRU inventory begins to decrease because of the additional demand for TRU from the second plant. It would go negative in year 26 , so the breeding ratio is increased to 0.55 in year 26 to prevent this. The stockpile has been completely processed by year 37 so that the only source of thermal spent fuel is the thermal reactors discharge of 41.4 MT/Yr. To supply enough TRU, the BR is increased to 0.75 in Year 36.

The reprocessing rates are shown in Figure 4(b). It decreases to meet the spent fuel available for reprocessing in Year 37. The site has reached a steady state of $60 \%$ reprocessing and will remain constant as long as two thermal reactors and two fast reactors operate at this site.

4.6. Site Conversion to Four Thermal, Two Fast Spectrum Plants $(B R=0.5)$. The minimum practical breeding ratio is about 0.5 [6]. Four thermal plants produce a total of $82.8 \mathrm{MT}$ of heavy metal. The $1 \%$ TRU in this fuel produces $0.828 \mathrm{MT}$ of TRU. Each fast reactor plant of breeding ratio 0.5 needs about $0.44 \mathrm{MT}$ of replacement TRU/yr so two fast reactor plants burn $0.88 \mathrm{MT} / \mathrm{Yr}$, a bit more than the four thermal plants produce. The added TRU needed at steady state can be obtained with a slight increase in breeding ratio above 0.5 . Thus, this scenario represents the maximum ratio of thermal plants to fast reactor plants.

The non-processed fuel for this scenario is shown in Figure 5(a). More than 40 years after the reprocessing plant startup is required to reach a steady state. The two fast reactors are started in years 5 and 18. The fast reactors are built before the third and fourth thermal reactors to minimize transient TRU inventory. Thermal plants one and two operate throughout either by life extensions or replacing the plants. The timing of thermal plants three and four is not critical. In this study, the third thermal plant is started in year 28 , ten years after the second fast reactor plant. It causes a noticeable bend in the nonprocessed fuel curve, Figure 5(a), since it is adding $20.7 \mathrm{MT} / \mathrm{yr}$. The fourth thermal plant is started in year 38, ten years after the third. The $100 \mathrm{MT} / \mathrm{Yr}$ reprocessing plant is now inadequate to process all the spent fuel so an additional $20 \mathrm{MT} / \mathrm{Yr}$ plant is added. Without this added capacity, the nonprocessed fuel starts to climb but with it, the nonprocessed fuel continues to decline. It declines until all the archived spent fuel has been processed. Then it becomes constant as the total reprocessing rate drops from the rated $120 \mathrm{MT} / \mathrm{Yr}$ to $101.4 \mathrm{MT} / \mathrm{yr}$, the steady state output from the thermal and fast reactors.

The reprocessing rate is shown in Figure 5(b). The additional $20 \mathrm{MT} / \mathrm{Yr}$, started in year 38, is needed until processing of the archived fuel is finished (year 45) when 


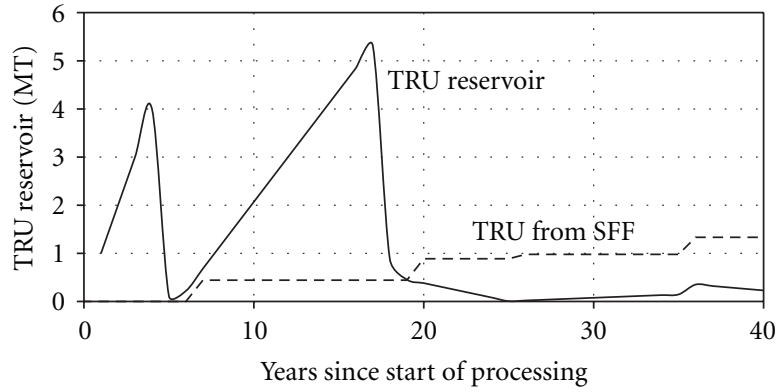

(a) TRU fuel reservoir

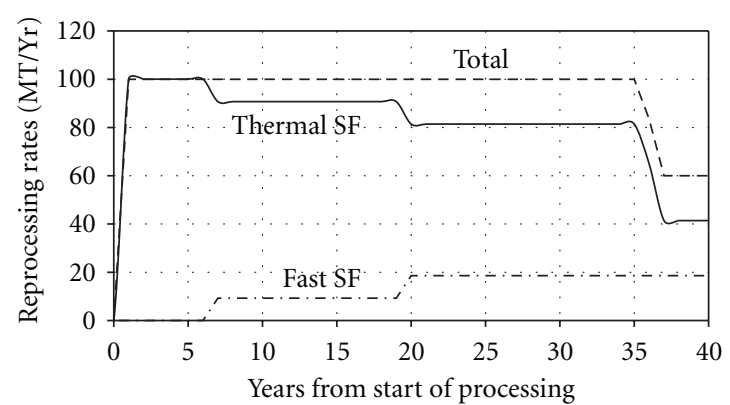

(b) Reprocessing rates

Figure 4: Conversion to two thermal, two fast spectrum plants $(\mathrm{BR}=0.5$, then to 0.55 and then 0.75$)$.

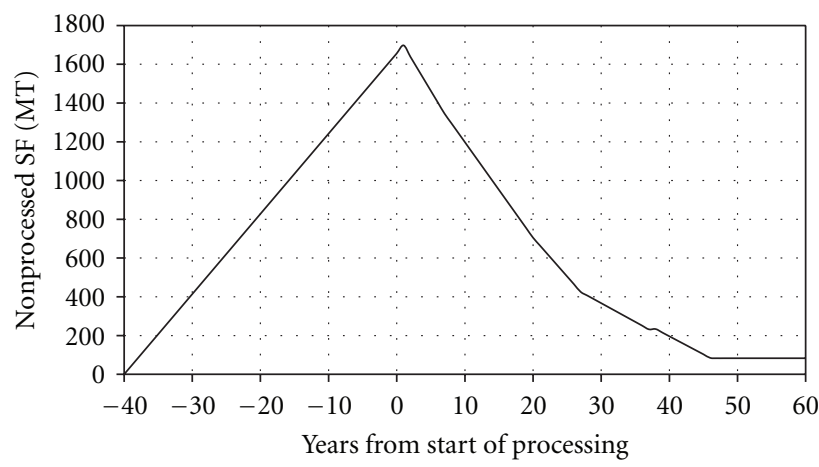

(a) Nonprocessed fuel

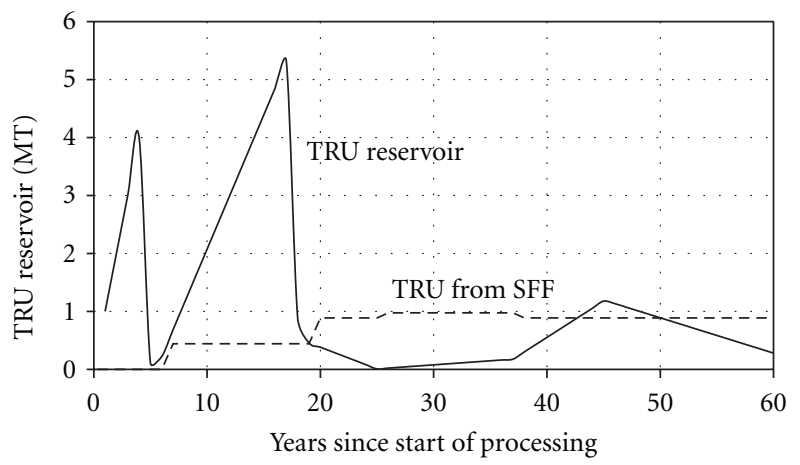

(c) TRU fuel reservoir

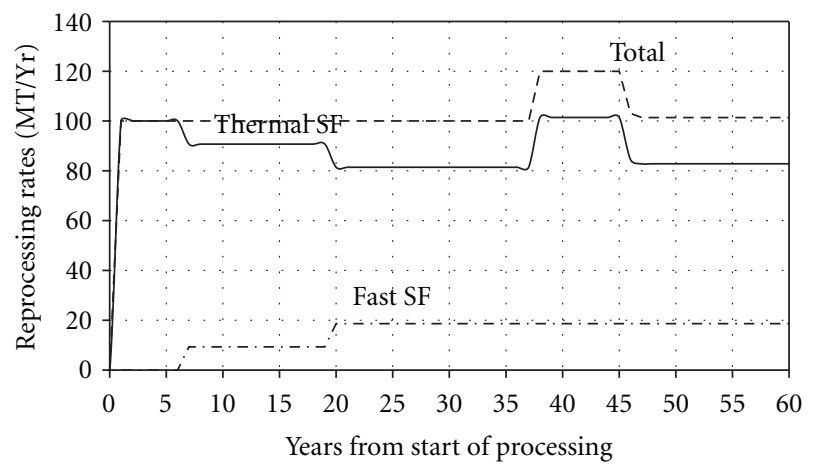

(b) Reprocessing rate

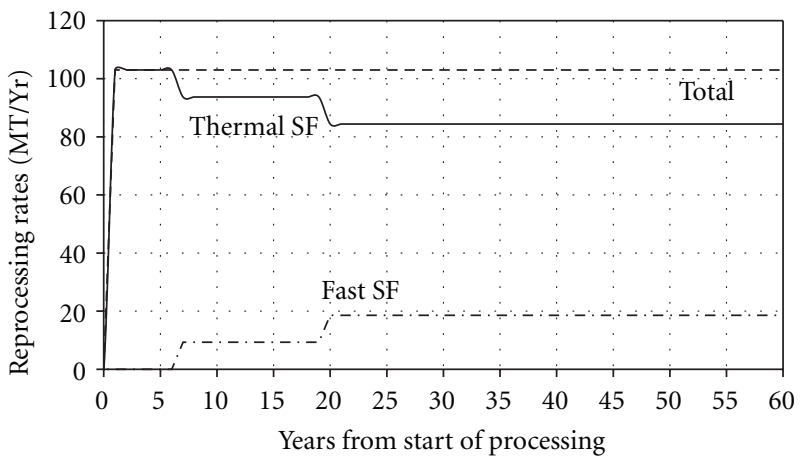

(d) Increased processing rate of $103 \mathrm{MT} / \mathrm{yr}$

Figure 5: Conversion to four thermal, two fast spectrum plants ( $\mathrm{BR}=0.5$, increased to 0.55 and then 0.5 ).

the reprocessing rate decreases to the steady state value of 101.4 MT/Yr. There is considerably more processing with this option and these costs plus continual new nuclear fuel costs must be weighed against the additional cost of fast reactors in the other scenarios.

The TRU reserve is shown in Figure 5(c). The startups of the two fast reactor plants are evidenced by sharp drops in the level. A slow decline occurs after the second plant comes on line due to the decrease in the available thermal processing. To keep the TRU reserve positive, the breeding ratio is increased to 0.55 in year 26 and kept at that value to year 38 when it is returned to 0.5 . The additional TRU needed then is supplied by the added $20 \mathrm{MT} / \mathrm{Yr}$ reprocessing plant. The TRU reserve then rises until year 46 when the archive thermal spent fuel is depleted when it decreases slowly. After year $46, \mathrm{BR}$ can be increased slightly to get a constant TRU reserve when the reservoir decreases to the desired amount.

Alternatively, the reprocessing plant can be built initially for $103 \mathrm{MT} / \mathrm{Yr}$ to yield a reprocessing rate curve that remains constant, as shown in Figure 5(d), until year 59 then drops a small amount. In this modification, the reprocessing plant is used at almost $100 \%$ continuously. It was necessary to increase the breeding ratio to 0.55 between years 42 and 46 to prevent having to transport TRU from off-site. 


\section{Conclusions}

The conversion of existing plant sites to nuclear islands would eliminate the need for long-term repository storage of plutonium. This conversion would not be done on a rush basis but over decades by beginning now with older sites reaching or having reached spent fuel storage capacity. If the conversion is carried out when each site reaches this stage, over the next 40 to 100 years, all of the existing commercial nuclear sites can be converted to nuclear islands. The conversion would be initiated at any given site with the construction of a $100 \mathrm{MT} / \mathrm{Yr}$ reprocessing plant. Fast reactors can be designed to produce the breeding ratio most conducive to either maintaining current power levels or increasing power to match increased electrical demands, and to either convert existing sites to all fast reactors or to keep the majority thermal. Scenarios have been investigated using, $\mathrm{BR}=0.5, \mathrm{BR}=1.0$, and $\mathrm{BR}=1.3$ to convert two thermal plant sites to nuclear islands with respectively two, four, or six fast reactors. In addition, scenarios were presented where two thermal reactor sites could be converted to two thermal reactors, two fast reactor nuclear islands or to four thermal reactors, two fast reactor nuclear islands. The latter case yields the $2 / 3$ rds thermal, $1 / 3$ rd fast reactor ratio, and is close to the maximum thermal to fast reactor ratio possible and still meets the no spent fuel shipping requirement.

Fast reactors must be part of a nuclear island to first sequester the TRU which exists in the spent nuclear fuel on-site and then to fission the annual production of spent fuel from thermal reactors and supply any additional TRU needed to run the fast reactors. Without the fast reactors, there can be no nuclear island. The criteria to select the best nuclear island conversion scenario would depend upon many factors, but primarily economics and how effectively the US intends to use its total uranium supply. In all of these examples, no spent fuel would ever have to be shipped off-site. Only fission products would be disposed of in Yucca Mountain. However, the last scenario, four thermal and two fast reactors, would leave a lot of wasted depleted uranium. The author would like to see the scenario adopted which converts two thermal reactors to six fast reactors since this most fully uses uranium and triples the nuclear power. Hopefully, the additional nuclear plants would be in place of fossil fuel plants. Detailed cost estimates of each scenario are beyond the scope of this paper, but the total cost of each may be similar per GWh. The all fast reactor options offer the advantage of reprocessing much less spent fuel than the two thermal reactor scenarios, but fast reactors are more expensive to build than thermal reactors (25\%). Reprocessing also produces cost savings since it decreases the volume which must be stored and the heat load which must be dissipated in Yucca Mountain by a factor of 5 .

\section{Acknowledgment}

This paper was supported by the US Department of Energy, Science, and Technology, under Contract W-31-109-eng-38.

\section{References}

[1] C. E. Till, Y. I. Chang, and W. H. Hannum, "The integral fast reactor-an overview," Progress in Nuclear Energy, vol. 31, no. 12, pp. 3-11, 1997.

[2] H. Nifenecker, D. Heuer, J. M. Loiseaux et al., "Scenarios with an intensive contribution of nuclear energy to the world energy supply," International Journal of Global Energy Issues, vol. 19, no. 1, pp. 63-77, 2003.

[3] T. J. Battisti, K. M. Goff, K. J. Bateman, M. F. Simpson, and J. P. Lind, "Ceramic waste form production and development at ANL-west," in Proceedings of the American Nuclear Society's 5th Topical Meeting on Spent Nuclear Fuel and Fissile Materials Management, Charleston, SC, USA, September 2002.

[4] C. E. Till and Y. I. Chang, "Evolution of the liquid metal reactor: the Integral Fast Reactor (IFR) concept," in Proceedings of the 51st American Power Conference, pp. 688-691, Chicago, Ill, USA, April 1989.

[5] C. W. Solbrig, M. J. Lineberry, and R. W. Benedict, "Repository storage strategy with central station reprocessing," in Proceedings of the International Congress on Advances in Nuclear Power Plants (ICAPP '03), Cordoba, Spain, May 2003.

[6] R. W. Benedict, C. Solbrig, B. Westphal et al., "Pyroprocessing progress at Idaho National Laboratory," in Proceedings of the Advanced Nuclear Fuel Cycles and Systems (ANS Global '07), pp. 741-747, Boise, Idaho, USA, September 2007.

[7] C. W. Solbrig and R. W. Benedict, "Cost savings of nuclear power with total fuel reprocessing," in Proceedings of the International Congress on Advances in Nuclear Power Plants (ICAPP '06), pp. 1965-1972, Reno, Nev, USA, June 2006.

[8] R. N. Hill, J. R. Wade, J. R. Liaw, and E. K. Fujita, "Physics studies of weapons plutonium disposition in the integral fast reactor closed fuel cycle," Nuclear Science and Engineering, vol. 121, no. 1, pp. 17-31, 1995. 

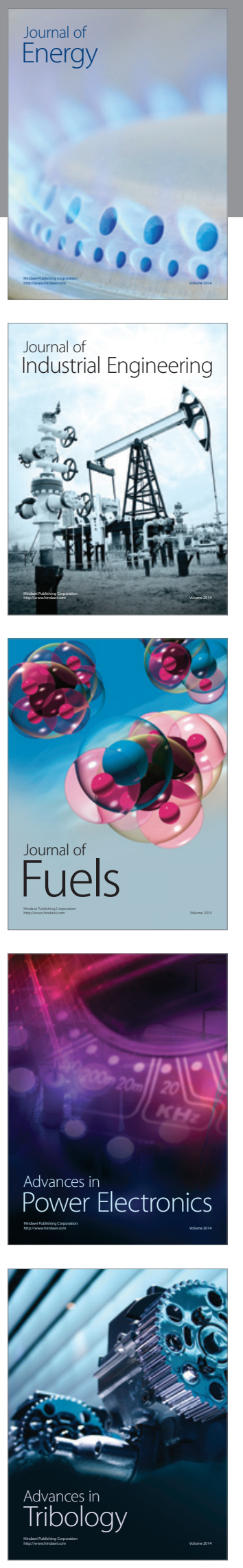
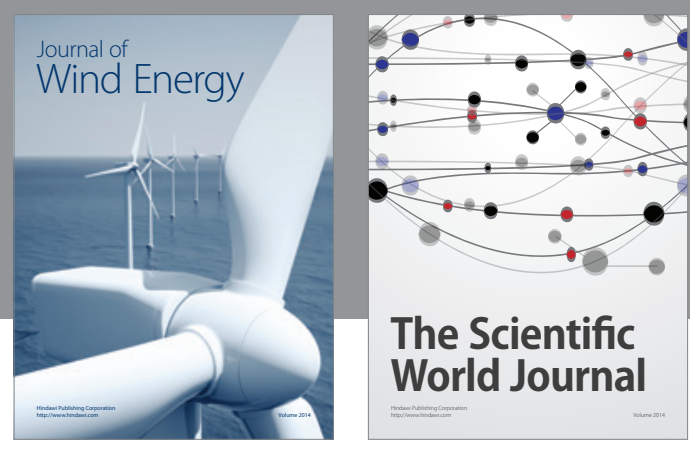

The Scientific World Journal

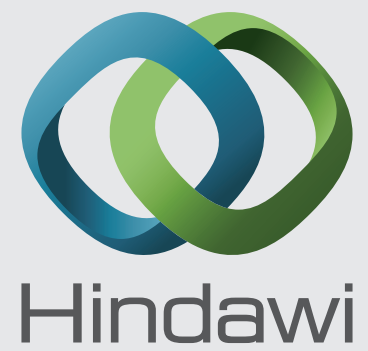

Submit your manuscripts at http://www.hindawi.com
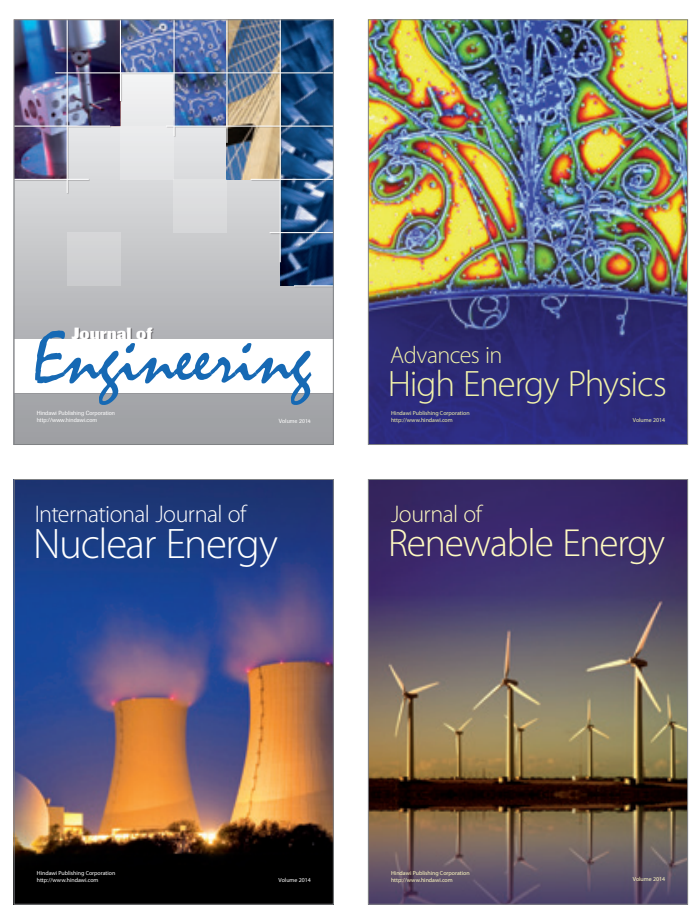

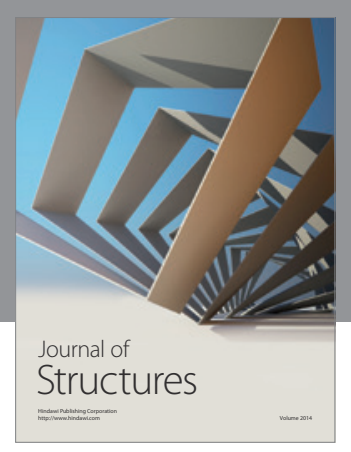

Rotating
Mechinery
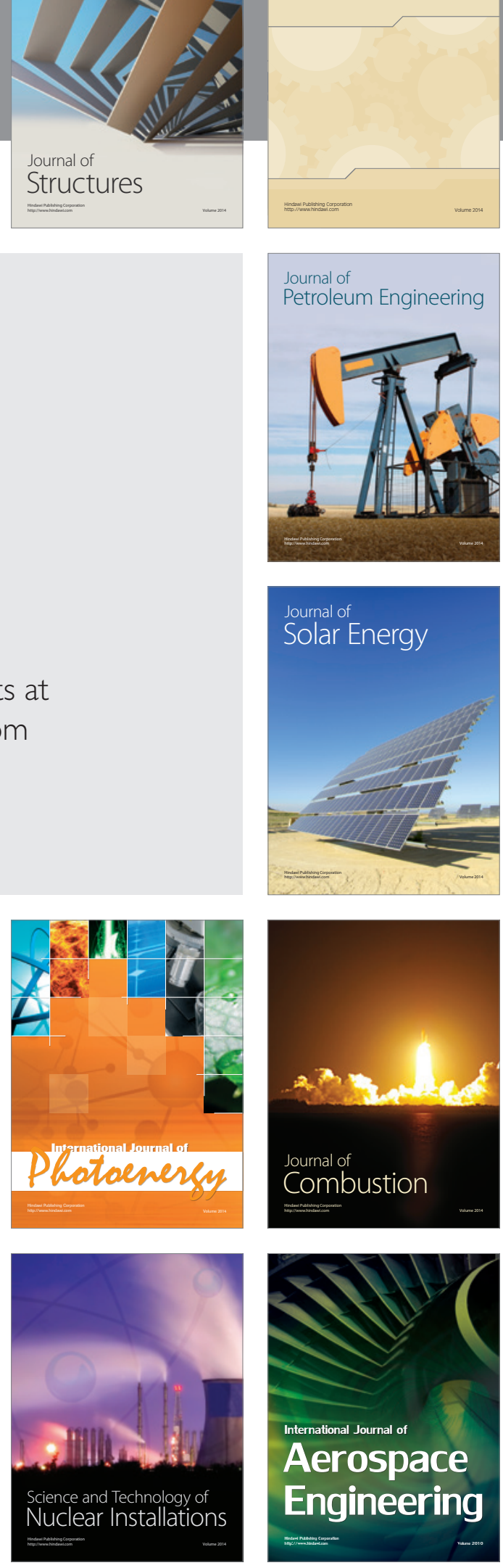